\title{
Diabetes and modifiable risk factors for cardiovascular disease: the prospective Million Women Study
}

\author{
Elizabeth A. Spencer $\cdot$ Kirstin L. Pirie $\cdot$ Richard J. Stevens • \\ Valerie Beral · Anna Brown · Bette Liu · Jane Green · \\ Gillian K. Reeves · Million Women Study Collaborators
}

Received: 16 July 2008/Accepted: 17 October 2008/Published online: 18 November 2008

(C) Springer Science+Business Media B.V. 2008

\begin{abstract}
To compare the effect of potentially modifiable lifestyle factors on the incidence of vascular disease in women with and without diabetes. In 1996-2001 over one million middle-aged women in the UK joined a prospective study, providing medical history, lifestyle and sociodemographic information. All participants were followed for hospital admissions and deaths using electronic recordlinkage. Adjusted relative risks (RRs) and incidence rates were calculated to compare the incidence of coronary heart disease and stroke in women with and without diabetes and by lifestyle factors. At recruitment 25,915 women (2.1\% of $1,242,338$ ) reported current treatment for diabetes. During a mean follow-up of 6.1 years per woman, 21,928 had a first hospital admission or death from coronary heart disease (RR for women with versus without diabetes $=3.30$, 95\% CI 3.14-3.47) and 7,087 had a first stroke $(\mathrm{RR}=2.47,95 \%$ CI 2.24-2.74). Adjusted incidence rates of these conditions in women with diabetes increased with duration of diabetes, obesity, inactivity and smoking. The 5 -year adjusted incidence rates for cardiovascular disease were 4.6 (95\% CI 4.4-4.9) per 100 women aged 50-69 in non-smokers with diabetes, 5.9 (95\% CI 4.6-7.6) in smokers with diabetes not using insulin and $11.0(95 \% \mathrm{CI}$ 8.3-14.7) in smokers with diabetes using insulin. Nonsmoking women with diabetes who were not overweight or inactive still had threefold increased rate for coronary disease or stroke compared with women without diabetes. Of the modifiable factors examined in middle aged women
\end{abstract}

E. A. Spencer $(\bowtie) \cdot$ K. L. Pirie - R. J. Stevens · V. Beral · A. Brown - B. Liu · J. Green · G. K. Reeves · Million Women Study Collaborators

Cancer Epidemiology Unit, University of Oxford,

Richard Doll Building, Oxford OX3 7LF, UK

e-mail: elizabeth.spencer@ceu.ox.ac.uk with diabetes, smoking causes the greatest increase in cardiovascular disease, especially in those with insulin treated diabetes.

Keywords Cardiovascular - Diabetes - Prospective · Body mass index $\cdot$ Physical activity $\cdot$ Smoking
Abbreviations
BMI Body mass index
CHD Coronary heart disease
CI Confidence interval
CVD Cardiovascular disease
RR Relative risk

\section{Introduction}

People with diabetes are at increased risk of coronary heart disease and stroke [1-13] but the effect of potentially modifiable lifestyle factors on the incidence of these conditions among people with diabetes is unclear, particularly for women. We report here on the incidence of coronary heart disease, stroke and pulmonary embolism in women with and without diabetes, overall and by smoking, body mass index (BMI), and physical activity in a large UK prospective study.

\section{Methods}

Participants and data

In 1996-2001 over one million women attending National Health Service (NHS) breast screening clinics in England and Scotland joined the Million Women Study by 
completing a self-administered questionnaire on lifestyle, physical activity, anthropometry, socio-demographic factors and medical history and gave written consent for follow-up [14]. We define women with diabetes as those who at recruitment reported being treated for diabetes. Information on insulin use and age at first treatment for diabetes was obtained from resurvey data collected around 3 years after recruitment, completed by approximately $65 \%$ of study participants.

Study participants are followed for hospital admissions, deaths and emigrations, by record-linkage, via their NHS number (a unique personal identifier for NHS records) and other personal details. Hospital admissions data are available from the Information Services Division of Scottish Morbidity Records since 1/1/1981 in Scotland [15] and from Hospital Episode Statistics since 1/4/1997 in England [16]. The primary reason for hospital admission and underlying cause of death were coded by those agencies providing data to us, using the WHO International Classification of Diseases 10th revision, ICD-10 [17].

The study was approved by the Anglia and Oxford Multi-Centre Research Ethics Committee. Access to hospital admission data was approved by the Information Services Division (Scotland) and the Information Centre for Health and Social Care (England).

\section{Statistical analysis}

The vascular disease endpoints examined in these analyses were first admission for or death from coronary heart disease (CHD) (ICD10 I20-25), stroke (ICD10 I60-69, including haemorrhagic stroke [ICD10 I60-62] and ischaemic stroke [ICD10 I63, I65, I66]), cardiovascular disease (CVD, defined as CHD or stroke) and pulmonary embolism (ICD10 I26). Women who had any of these conditions prior to recruitment were excluded from all analyses and women who had these conditions prior to resurvey were excluded from analyses using the resurvey data.

Person-years were calculated from date of recruitment (or in England from 1/4/1997 for the 5\% of the cohort who were recruited before that date, as hospital data were unavailable before then) up to the soonest of hospital admission for any of the endpoints, death, or last date of follow-up (31/12/03 in Scotland and 31/3/05 in England). For analyses on insulin use and age at first treatment of diabetes, person-years commenced on the date that women completed the resurvey questionnaire.

Relative risks (RRs) and 95\% confidence intervals (CIs) were calculated by Cox proportional hazards models using attained age as the underlying time variable, using Stata release 9.2 (Stata Corporation, TX, USA). Analyses were stratified by 10 geographic regions and quintiles of socioeconomic status as described previously [18] and adjusted by alcohol consumption (none, one, two or more alcoholic drinks per day) and, where appropriate, by smoking (never, past, current $<15$ cigarettes/day, current $15+$ cigarettes/ day). Some analyses were additionally adjusted by body mass index (BMI) (less than $22.5 \mathrm{~kg} / \mathrm{m}^{2}, 22.5-25 \mathrm{~kg} / \mathrm{m}^{2}$, $25-27.5 \mathrm{~kg} / \mathrm{m}^{2}, 27.5-30 \mathrm{~kg} / \mathrm{m}^{2}, 30-32.5 \mathrm{~kg} / \mathrm{m}^{2}, 32.5+\mathrm{kg} /$ $\mathrm{m}^{2}$ ), physical activity (inactive [strenuous exercise rarely/ never], active [strenuous exercise once or more/week]), hypertension (yes, no) and high cholesterol (yes, no). Women with missing values for any adjustment variable were assigned to a separate category for that variable, and sensitivity analyses were also done restricted to women with known values.

Standardised incidence rates per 100 women aged 50-69 years over 5 years were calculated, taking women without diabetes as the standard, and standardising by age, region, socio-economic status, alcohol consumption and smoking, among women categorised by diabetes, BMI, physical activity and smoking. Confidence intervals were estimated using the floating absolute risks method [19].

\section{Results}

Table 1 shows characteristics at recruitment of 1,242,338 women included in these analyses, of whom 25,915 (2.1\%) were treated for diabetes. Women with diabetes had higher BMI than those without diabetes (46\% versus $17 \%$ obese), and were more likely to be inactive (62\% versus $48 \%)$. Smoking prevalence was similar in the two groups $(18 \%$ versus $20 \%$ ). Women with diabetes requiring insulin therapy were less likely than all women with diabetes to be obese, inactive or to smoke.

The cohort was followed for an average of 6.1 years per woman. During this period 21,928 women had incident CHD, 7,087 had incident stroke and 2,938 had incident pulmonary embolism.

Women with diabetes were at a substantially greater risk of coronary heart disease $(\mathrm{RR}=3.30,95 \%$ CI 3.14-3.47) and stroke $(\mathrm{RR}=2.47,95 \%$ CI 2.24-2.74) than women without diabetes (Table 2). Among those with diabetes there was increased incidence of ischaemic stroke $(\mathrm{RR}=3.28,95 \%$ CI 2.84-3.79) but not of haemorrhagic stroke $(\mathrm{RR}=0.91,95 \%$ CI 0.69-1.21), although the specific type of stroke had not been coded for all women (Table 2). There was no significant increase in incident pulmonary embolism in women with, compared to without, diabetes $(\mathrm{RR}=1.09,95 \%$ CI 0.87-1.36). Analyses were repeated additionally adjusting for BMI, physical activity, hypertension and high cholesterol (Table 2), which lowered the relative risks. Since these additional adjustment factors are likely to be on the causal pathway for vascular disease, subsequent analyses have not adjusted for them. 
Table 1 Characteristics of study participants at baseline and details of follow-up

\begin{tabular}{|c|c|c|c|c|}
\hline & $\begin{array}{l}\text { All women } \\
n=1,242,338\end{array}$ & $\begin{array}{l}\text { Women without diabetes } \\
n=1,216,423\end{array}$ & $\begin{array}{l}\text { Women with diabetes } \\
n=25,915\end{array}$ & $\begin{array}{l}\text { Women with diabetes } \\
\text { using insulin }{ }^{\mathrm{b}} n=4,564\end{array}$ \\
\hline \multicolumn{5}{|l|}{ Characteristics at baseline $^{\mathrm{a}}$} \\
\hline Mean age $(\mathrm{SD})$, years & $56.0(4.8)$ & $56.0(4.8)$ & $57.6(4.9)$ & $56.6(4.8)$ \\
\hline Mean BMI (SD), $\mathrm{kg} / \mathrm{m}^{2}$ & $26.1(4.6)$ & $26.1(4.6)$ & $30.1(6.1)$ & $28.9(6.2)$ \\
\hline$\%$ obese $(n)$, BMI $30+\mathrm{kg} / \mathrm{m}^{2}$ & $17(203,306)$ & $17(192,298)$ & $46(11,008)$ & $37(1,598)$ \\
\hline$\%$ inactive $(n)$ & $48(572,992)$ & $48(557,726)$ & $62(15,266)$ & $56(2,467)$ \\
\hline$\%$ current smoker $(n)$ & $20(238,899)$ & $20(234,514)$ & $18(4,385)$ & $14(615)$ \\
\hline Mean alcohol intake (SD), g/day & $6.3(7.6)$ & $6.4(7.6)$ & $3.3(5.7)$ & $4.1(6.2)$ \\
\hline$\%$ in lowest third of socio-economic status $(n)$ & $33(410,591)$ & $33(398,810)$ & $46(11,781)$ & $39(1,749)$ \\
\hline$\%$ hypertension $(n)$ & $23(283,154)$ & $22(270,070)$ & $51(13,084)$ & $44(2,025)$ \\
\hline$\%$ high cholesterol $(n)$ & $10(118,392)$ & $9(111,347)$ & $27(7,045)$ & $24(1,104)$ \\
\hline$\%$ currently using HRT $(n)$ & $34(413,669)$ & $34(407,242)$ & $25(6,427)$ & $31(1,420)$ \\
\hline Mean height (SD), cm & $162.0(6.7)$ & $162.0(6.7)$ & $161.3(7.0)$ & $162.2(6.9)$ \\
\hline \multicolumn{5}{|l|}{ Follow-up } \\
\hline Person-years of follow-up (in thousands) & 7,552 & 7,401 & 151 & $13^{\mathrm{b}}$ \\
\hline Women with first coronary event $(n)$ & 21,928 & 20,198 & 1,730 & 207 \\
\hline Women with first stroke $(n)$ & 7,087 & 6,678 & 409 & 47 \\
\hline Women with first pulmonary embolism $(n)$ & 2,938 & 2,860 & 78 & 6 \\
\hline
\end{tabular}

a Totals do not always agree because of small numbers of missing values

${ }^{\mathrm{b}}$ Information on insulin treatment available from a resurvey of 760,688 women; person-years commence at date of resurvey (see Methods)

Table 2 Relative risk of first hospital admission or death from certain vascular diseases in women with diabetes compared with women without diabetes

\begin{tabular}{llrr}
\hline & $\begin{array}{l}\text { Number of women with a } \\
\text { first vascular event }\end{array}$ & $\mathrm{RR}^{\mathrm{a}}(95 \% \mathrm{CI})$ & $\mathrm{RR}^{\mathrm{b}}(95 \% \mathrm{CI})$ \\
\hline & With/without diabetes & & \\
CHD & $1,730 / 20,198$ & $3.30(3.14-3.47)$ & $2.44(2.32-2.57)$ \\
Stroke (all types) & $409 / 6,678$ & $2.47(2.24-2.74)$ & $2.08(1.88-2.31)$ \\
$\quad$ Haemorrhagic stroke & $49 / 2,457$ & $0.91(0.69-1.21)$ & $0.87(0.65-1.16)$ \\
Ischaemic stroke & $204 / 2,368$ & $3.28(2.84-3.79)$ & $2.55(2.19-2.96)$ \\
$\quad$ Other and unspecified stroke & $156 / 1,853$ & $3.17(2.69-3.75)$ & $2.60(2.19-3.08)$ \\
Pulmonary embolism & $78 / 2,860$ & $1.09(0.87-1.36)$ & $0.84(0.67-1.05)$ \\
\hline
\end{tabular}

a Adjusting by age, region, socio-economic status, alcohol consumption and smoking

b Adjusting by age, region, socio-economic status, alcohol consumption, smoking, BMI, physical activity, hypertension and high cholesterol

In sensitivity analyses restricted to women with known values for all adjustment variables, the relative risk for coronary heart disease was 3.25 (95\% CI 3.08-3.42) and the relative risk for stroke was 2.52 (95\% CI 2.27-2.80). When analyses were repeated defining diabetes by selfreported history of diabetes, instead of diabetes treatment, the relative risk for coronary heart disease was 3.18 (95\% CI 3.03-3.34) and the relative risk for stroke was 2.32 (95\% CI 3.03-3.34).

Women with diabetes requiring insulin therapy were at greater risk of coronary heart disease and stroke than women with diabetes not using insulin (Table 3). Compared to women without diabetes, relative risks for coronary heart disease were 2.69 (95\% CI 2.38-3.05) among women with diabetes not using insulin and 4.80 (95\% CI 4.18-5.52) among women using insulin. The corresponding relative risks were 1.74 (95\% CI 1.32-2.28) and 3.68 (95\% CI 2.75-4.92) for stroke. Longer-standing disease, as indicated by younger age at first treatment, was also associated with greater increases in risk for coronary heart disease and stroke (Table 3). Age at first treatment and current insulin use had independent influences on the risk of vascular disease. Compared to women without diabetes, the relative risks for cardiovascular disease in women with diabetes first treated before age 50 were 3.48 (95\% CI 2.71-4.47) in those not using insulin and 5.44 (95\% CI 4.61-6.43) in those using insulin; and among women first treated for diabetes at age 50 or older, the 
Table 3 Relative risk of first hospital admission or death from CHD or stroke, by insulin treatment and by age of first treatment for diabetes ${ }^{\mathrm{a}}$

\begin{tabular}{|c|c|c|c|}
\hline & $\begin{array}{l}\text { Number of women } \\
\text { with an event }\end{array}$ & $\begin{array}{l}\text { Number of eligible } \\
\text { study participants }^{\mathrm{a}}\end{array}$ & $\mathrm{RR}^{\mathrm{b}}(95 \% \mathrm{CI})$ \\
\hline \multicolumn{4}{|l|}{ Coronary heart disease } \\
\hline No diabetes & 6,507 & 747,473 & 1.00 (reference) \\
\hline Diabetes with insulin treatment & 207 & 4,564 & $4.80(4.18-5.52)$ \\
\hline Diabetes without insulin treatment & 270 & 8,651 & $2.69(2.38-3.05)$ \\
\hline Diabetes first treated before age 30 years & 44 & 885 & $6.84(5.08-9.20)$ \\
\hline Diabetes first treated at age $30-39$ years & 31 & 675 & $5.63(3.96-8.02)$ \\
\hline Diabetes first treated at age $40-49$ years & 95 & 2,456 & $4.50(3.67-5.51)$ \\
\hline Diabetes first treated at age $50+$ years & 215 & 6,842 & $2.59(2.26-2.97)$ \\
\hline \multicolumn{4}{|l|}{ Stroke } \\
\hline No diabetes & 2,043 & 747,473 & 1.00 (reference) \\
\hline Diabetes with insulin treatment & 47 & 4,564 & $3.68(2.75-4.92)$ \\
\hline Diabetes without insulin treatment & 54 & 8,651 & $1.74(1.32-2.28)$ \\
\hline Diabetes first treated before age 30 years & 6 & 885 & $3.10(1.39-6.91)$ \\
\hline Diabetes first treated at age $30-39$ years & 6 & 675 & $3.41(1.53-7.60)$ \\
\hline Diabetes first treated at age $40-49$ years & 22 & 2,456 & $3.64(2.38-5.55)$ \\
\hline Diabetes first treated at age $50+$ years & 47 & 6,842 & $1.84(1.37-2.46)$ \\
\hline
\end{tabular}

${ }^{\text {a }}$ Information on insulin treatment and age at first treatment obtained from a resurvey of women 3 years after recruitment, completed by approximately $65 \%$ of study participants; person-years commence at date of resurvey; women were excluded from these analyses if they had a first vascular event before that date, leaving 760,688 eligible for these analyses (see Methods)

b Adjusted by age, region, socio-economic status, alcohol consumption and smoking

relative risks were $2.14(95 \%$ CI $1.85-2.48)$ in those not using insulin and 3.22 (95\% CI 2.56-4.04) in those using insulin.

Among women without diabetes, the 5-year incidence rate for coronary heart disease was 1.32 (95\% CI 1.301.34) per 100 women aged 50-69 and the corresponding incidence rate for stroke was 0.43 (95\% CI 0.42-0.44). Among women with diabetes the 5-year standardised incidence rates per 100 women were 4.34 (95\% CI 4.134.57) for coronary heart disease and 1.06 (95\% CI $0.96-$ 1.17) for stroke. Table 4 shows standardised incidence rates by BMI, physical activity and smoking, for women with and without diabetes. In women without diabetes, the incidence rates of both coronary heart disease and stroke increased with increasing BMI, with inactivity and with smoking, and at each level of these factors women with diabetes have higher incidence rates than women without diabetes-usually 2-3 times higher.

Figure 1 shows incidence rates for cardiovascular disease (CVD) by BMI, physical activity and smoking, in women with and without diabetes, controlling for age, region, socio-economic status, alcohol consumption and smoking. The excess incidence of CVD in women with diabetes is greatest among smokers: 5-year incidence rates were 4.6 (95\% CI 4.4-4.9) and 8.1 (95\% CI 7.5-8.9) per 100 women aged 50-69 years, respectively, in never- smokers with diabetes and current smokers with diabetes. There is little difference in CVD incidence between neversmokers and past smokers among women with diabetes.

The excess cardiovascular disease incidence among smokers with diabetes compared to non-smokers with diabetes is greatest of all among those using insulin (Fig. 2). The 5-year incidence rate for CVD is 5.9 (95\% CI 4.6-7.6) per 100 women aged 50-69 among those with diabetes not using insulin who smoke. Among women with diabetes who use insulin and who smoke, the incidence rate is 11.0 (95\% CI 8.3-14.7). In other words, among middleaged women with diabetes, 1 in 22 non-smokers have incident cardiovascular disease over a 5 year period, increasing to 1 in 17 for smokers whose diabetes does not require insulin and 1 in 9 for smokers with diabetes requiring insulin treatment.

At all levels of the modifiable factors BMI, physical activity and smoking, women with diabetes are still at a substantially higher risk of vascular disease than women without diabetes. Even in the lowest category of risk, i.e. among physically active, never-smoking women with BMI $<25 \mathrm{~kg} / \mathrm{m}^{2}$, the 5 -year incidence rate of cardiovascular disease is 2.4 (95\% CI 1.8-3.2) per 100 women aged 50-69 in those with diabetes, 3 times higher than the corresponding incidence rate of 0.8 (95\% CI 0.8-0.8) in similar women without diabetes. 
Table 4 Standardised Incidence rates ${ }^{\mathrm{a}}$ per 100 women aged 50-69 years over a 5-year period (and 95\% CI) of first hospital admission or death from coronary heart disease or stroke among women with and without diabetes

\begin{tabular}{|c|c|c|c|c|}
\hline & \multicolumn{2}{|l|}{ Coronary heart disease } & \multicolumn{2}{|l|}{ Stroke } \\
\hline & Women without diabetes & Women with diabetes & Women without diabetes & Women with diabetes \\
\hline \multicolumn{5}{|c|}{ Body mass index $\left(\mathrm{kg} / \mathrm{m}^{2}\right)$} \\
\hline$<25$ & $1.0(1.0-1.1)$ & $3.7(3.3-4.2)$ & $0.4(0.4-0.4)$ & $1.0(0.8-1.2)$ \\
\hline Number of events & 7,226 & 290 & 2,818 & 75 \\
\hline $25-30$ & $1.4(1.4-1.4)$ & $4.5(4.1-4.9)$ & $0.4(0.4-0.4)$ & $1.0(0.8-1.2)$ \\
\hline Number of events & 7,503 & 571 & 2,235 & 121 \\
\hline $30+$ & $1.7(1.6-1.7)$ & $4.2(3.9-4.5)$ & $0.5(0.5-0.5)$ & $1.1(1.0-1.3)$ \\
\hline Number of events & 4,261 & 719 & 1,172 & 177 \\
\hline \multicolumn{5}{|l|}{ Physical activity } \\
\hline Active & $1.0(1.0-1.0)$ & $3.6(3.3-3.9)$ & $0.3(0.3-0.3)$ & $0.8(0.6-0.9)$ \\
\hline Number of events & 7,787 & 517 & 2,613 & 108 \\
\hline Inactive & $1.3(1.3-1.3)$ & $4.0(3.8-4.2)$ & $0.4(0.4-0.4)$ & $1.0(0.9-1.2)$ \\
\hline Number of events & 11,402 & 1,092 & 3,729 & 272 \\
\hline \multicolumn{5}{|l|}{ Smoking } \\
\hline Never smoker & $0.9(0.9-1.0)$ & $3.6(3.3-3.9)$ & $0.3(0.3-0.3)$ & $0.9(0.8-1.0)$ \\
\hline Number of events & 7,136 & 701 & 2,260 & 174 \\
\hline Past smoker & $1.3(1.3-1.3)$ & $4.1(3.7-4.5)$ & $0.4(0.3-0.4)$ & $0.8(0.7-1.0)$ \\
\hline Number of events & 5,094 & 477 & 1,499 & 96 \\
\hline Current smoker & $2.4(2.3-2.4)$ & $6.4(5.8-7.0)$ & $0.9(0.9-0.9)$ & $1.9(1.6-2.3)$ \\
\hline Number of events & 6,890 & 406 & 2,567 & 115 \\
\hline
\end{tabular}

a Standardised by age, region, socio-economic status, alcohol consumption and, where appropriate, smoking

Fig. 1 Standardised incidence rates (standardised for age, region, socio-economic status, alcohol consumption and, where appropriate, smoking) of first hospital admission or death from cardiovascular disease per 100 women aged $50-69$ years over 5 years, by lifestyle factors

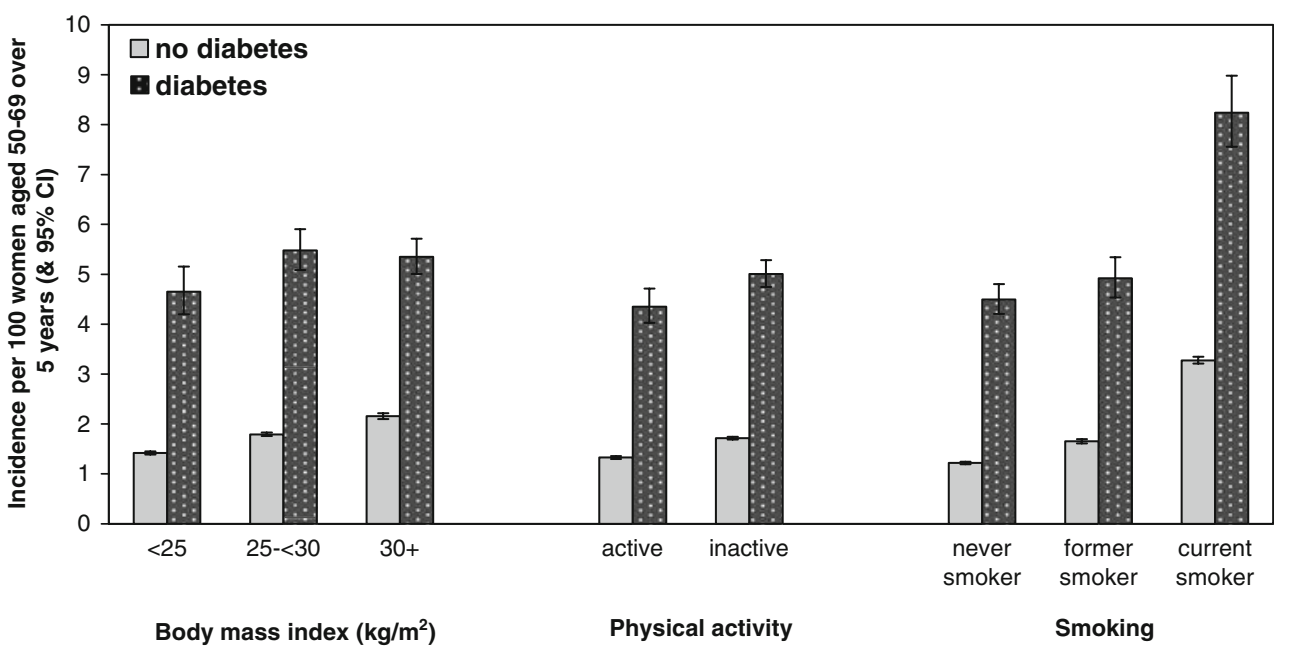

of prospective studies [1], other smaller prospective studies [2-12] and a large case-control study [13].

With large numbers of cardiovascular disease events we had sufficient statistical power to compare incidence rates reliably across different levels of potentially modifiable lifestyle factors: BMI, physical activity and smoking. While the incidence of cardiovascular disease in women with diabetes increased with increasing BMI, physical inactivity and smoking, the greatest excess incidence was 


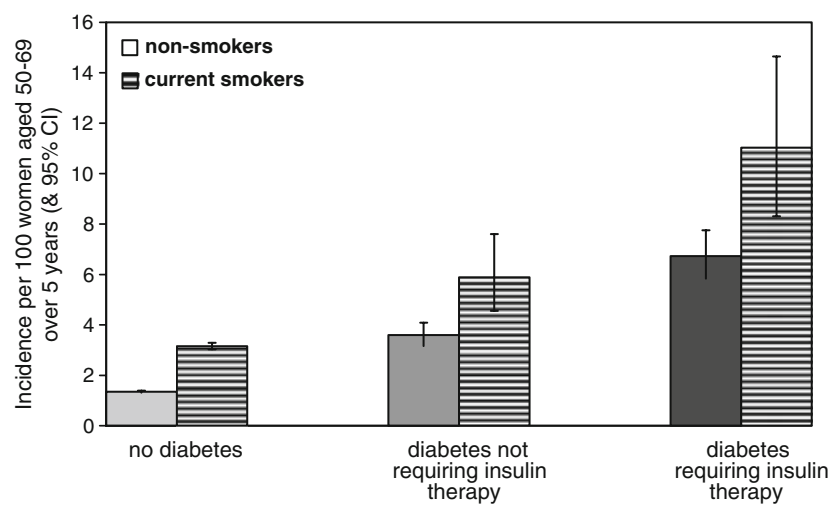

Fig. 2 Standardised Incidence rates (standardised for age, region, socio-economic status and alcohol consumption) of hospital admission or death from cardiovascular disease per 100 women aged 50-69 years over 5 years by smoking and diabetes

seen among smokers (Fig. 1). Three prospective studies of men with diabetes reported higher coronary heart disease or cardiovascular disease mortality in smokers than nonsmokers [3, 11, 12]; two of these also reported higher coronary heart disease mortality in men with increasing BMI $[3,11]$ and one reported higher coronary heart disease mortality with physical inactivity [11]. To our knowledge this is the first prospective study to describe the effects of lifestyle factors on vascular disease incidence in women with and without diabetes and the largest prospective study to estimate incidence rates for coronary heart disease and stroke among women with and without diabetes.

Of the potentially modifiable lifestyle factors examined here, smoking was associated with the greatest excess incidence of coronary heart disease or stroke, especially among women with severe diabetes requiring insulin therapy. UK guidelines on the management of diabetes include smoking cessation advice [20]. However, $18 \%$ of women with diabetes in this cohort were current smokers, similar to the figure of $20 \%$ among women without diabetes. Since cardiovascular disease incidence in past and never-smokers with diabetes was similar, aiding women with diabetes (especially those with diabetes requiring insulin therapy) to stop smoking could bring substantial benefits.

Although lifestyle factors can importantly modify the incidence of vascular diseases, diabetes itself has a major effect on these conditions. Even among non-smoking, physically active women who are not overweight, those with diabetes have cardiovascular disease incidence rates three times higher than women without diabetes.

We defined women with diabetes as those who reported when they joined the study that they were being treated for diabetes. Self-reported diabetes has been shown to be reliable in this and other studies [21, 22]. In a study of agreement between general practice prescription data and treatment for diabetes among 570 women in the Million Women Study, agreement was $98 \%$ with a kappa value of 0.78 [21]. Although this estimate was based on a small number of women with diabetes, this gives reassurance that the accuracy of self-reported diabetes treatment is good.

Whereas 25,915 women reported being treated for diabetes, 29,034 women reported that they had ever been diagnosed with diabetes. In addition, a small number of women would have developed diabetes after joining the study. Findings were essentially unchanged when we repeated the analyses using the 29,034 women who reported that they had ever been diagnosed with diabetes, and the small number who developed diabetes during follow-up would have little effect on the estimated incidence rates in women without diabetes, as these are based on over one million women.

No information was available on the type of diabetes women had. We did, however, have information on insulin use and age at first treatment of diabetes, collected at resurvey about 3 years after the study began. Most women in this study were diagnosed with diabetes after they were 50 years old and are thus likely to have type 2 diabetes, whereas those first treated before age 30 are likely to have type 1 diabetes. Our results show higher risks of coronary heart disease and stroke the younger women were when first treated for diabetes, but we cannot tell if this reflects long duration of diabetes or a specific effect of type 1 diabetes. We also found higher rates of coronary heart disease and stroke among women with diabetes who were using insulin: this reflects the fact that insulin use is a marker of severe disease. Randomised trials have shown that insulin itself does not increase risk for vascular disease in people with diabetes $[23,24]$.

To avoid confounding we adjusted analyses by age, region, socio-economic status, alcohol consumption and smoking. Additional adjustment for hypertension and high cholesterol attenuated the relative risks associated with diabetes. However, we did not routinely adjust for hypertension or high cholesterol since these are likely to be on the causal pathway to coronary heart disease and stroke.

The Million Women Study includes about one in four UK women who were aged 50-64 years at the time of recruitment and previous reports have shown that women participating in the Million Women Study differ little from the general UK population of women of a similar age [14, 25]. As study participants were recruited via UK National Health Service screening services, the ascertainment of outcomes through NHS hospital databases is likely to be largely complete. Linkage to information on NHS hospital admissions and deaths was via each participant's NHS number and other personal identifiers. This linkage has been shown to be good and follow-up for death is virtually complete [26-29]. 
This study demonstrates the large effect that diabetes has on the incidence of coronary heart disease and stroke among middle-aged women. It also shows that lifestyle factors can modify vascular disease incidence among women with diabetes and highlights how important it is for women with diabetes not to smoke.

Acknowledgments We thank the many women who completed questionnaires for this study, staff at the collaborating breast screening units and the Million Women Study coordinating centre and the Information and Statistics Division in Scotland and the Information Centre for Health and Social Care for access to hospital admissions data. The Million Women Study is supported by Cancer Research UK, the Medical Research Council, and the NHS Breast Screening Programme. The researchers act independently of the funders.

\section{References}

1. Lee WL, Cheung AM, Cape D, Zinman B. Impact of diabetes on coronary artery disease in women and men. Diabetes Care. 2000;23:962-8. doi:10.2337/diacare.23.7.962.

2. Asia Pacific Cohort Studies Collaboration. The effects of diabetes on the risks of major cardiovascular diseases and death in the Asia-Pacific region. Diabetes Care. 2003;26:360-6. doi:10.2337/ diacare.26.2.360.

3. Adlerberth AM, Rosengren A, Wilhelmsen L. Diabetes and longterm risk of mortality from coronary and other causes in middleaged Swedish men. Diabetes Care. 1998;21:539-45. doi:10.2337/ diacare.21.4.539.

4. Almdal T, Scharling H, Skov Jensen J, Vestergaard H. The independent effect of Type 2 diabetes mellitus on ischemic heart disease, stroke and death. Arch Intern Med. 2004;164:1422-6. doi:10.1001/archinte.164.13.1422.

5. Barrett-Connor EL, Cohn BA, Wingard DL, Edelstein SL. Why is diabetes mellitus a stronger risk factor for fatal ischemic heart disease in women than in men? The Rancho Bernardo Study. JAMA. 1991;265:627-31. doi:10.1001/jama.265.5.627.

6. Folsom AR, Rasmussen ML, Chambless LE, Howard G, Cooper LS, Shmidt MI, et al. Prospective associations of fasting insulin, body fat distribution, and diabetes with risk of ischemic stroke. Diabetes Care. 1999;22:1077-83. doi:10.2337/diacare.22.7.1077.

7. Gu K, Cowie CC, Harris MI. Mortality in adults with and without diabetes in a national cohort of the US population 1971-1993. Diabetes Care. 1998;21:1138-45. doi:10.2337/diacare.21.7.1138.

8. Hu FB, Stampfer MJ, Solomon CG, Liu S, Willett W, Speizer FE, et al. The impact of diabetes mellitus on mortality from all causes and CHD in women. Arch Intern Med. 2001;161:1717-23. doi: 10.1001/archinte.161.14.1717.

9. Janghorbani M, Hu FB, Willett WC, Li TY, Manson JE, Logroscino $G$, et al. Prospective study of Type 1 and Type 2 diabetes and risk of stroke subtypes. Diabetes Care. 2007; 30:1730-5. doi:10.2337/dc06-2363.

10. Kannel WB, McGee DL. Diabetes and cardiovascular disease. The Framingham study. JAMA. 1979;241:2035-8. doi:10.1001/ jama.241.19.2035.

11. Lotufo PA, Gaziano M, Chae CU, Ajani U, Moreno-John G, Buring JE, et al. Diabetes and all-cause and CHD mortality among US male physicians. Arch Intern Med. 2001;161:242-7. doi:10.1001/archinte.161.2.242.

12. Stamler J, Vaccaro O, Neaton JD, Wentworth D, Multiple Risk Factor Intervention Trial Research Group. Diabetes, other risk factors, and 12-yr cardiovascular mortality for men screened in the multiple risk factor intervention trial. Diabetes Care. 1993;16:434-43. doi:10.2337/diacare.16.2.434.

13. Yusuf S, Hawken S, Ounpuu S, Dans T, Avezum A, Lanas F, et al. Effect of potentially modifiable risk factors associated with myocardial infarction in 52 countries (the INTERHEART study): case-control study. Lancet. 2004;364:937-52. doi:10.1016/ S0140-6736(04)17018-9.

14. The Million Women Study Collaborative Group. The Million Women Study: design and characteristics of the study population. Breast Cancer Res. 1999;1:73-80. doi:10.1186/bcr16.

15. Information and Services Division. Scotland [homepage on the Internet] [cited 14 Jan 2008]. Available from: http://www.isdscot land.org/isd/CCC_FirstPage.jsp.

16. Hospital Episode Statistics [homepage on the Internet] [cited 14 Jan 2008]. Available from http://www.hesonline.nhs.uk/.

17. World Health Organization. International Statistical Classification of Diseases and Related Health Problems, vol. 1. Geneva: World Health Organization; 1992.

18. Reeves GK, Pirie K, Beral V, Green J, Spencer E, Bull D, et al. Cancer incidence and mortality in relation to BMI in the Million Women Study: cohort study. BMJ. 2007;335:1134-45. doi: 10.1136/bmj.39367.495995.AE.

19. Easton DF, Peto J, Babiker AG. Floating absolute risk: an alternative to relative risk in survival and case-control analysis avoiding an arbitrary reference group. Stat Med. 1991;10:102535. doi:10.1002/sim.4780100703.

20. McIntosh A, Hutchinson A, Home PD, Brown F, Bruce A, Damerell A, et al. Clinical guidelines and evidence review for Type 2 diabetes: management of blood glucose. Sheffield: ScHARR, University of Sheffield; 2001.

21. Banks E, Beral V, Cameron R, Hogg A, Langley N, Barnes I, et al. Agreement between general practice prescription data and self-reported use of hormone replacement therapy and treatment for various illnesses. J Epidemiol Biostat. 2001;6:357-63. doi: 10.1080/13595220152601837.

22. Bush TL, Miller SR, Golden AL, Hale WE. Self-report and medical record agreement of selected medical conditions in the elderly. Am J Public Health. 1989;79:1554-6.

23. UK Prospective Diabetes Study Group. Intensive blood-glucose control with sulphonylureas or insulin compared with conventional treatment and risk of complications in patients with type 2 diabetes (UKPDS 33). Lancet. 1998;352:837-53. doi:10.1016/ S0140-6736(98)07019-6.

24. Nathan DM, Cleary PA, Backlund JYC, Genuth SM, Lachin JM, Orchard TJ, et al. Intensive diabetes treatment and cardiovascular disease in patients with type 1 diabetes. $\mathrm{N}$ Engl $\mathrm{J}$ Med. 2005;353:2643-53. doi:10.1056/NEJMoa052187.

25. Banks E, Beral V, Cameron R, Hogg A, Langley N, Barnes I, et al. Comparison of various characteristics of women who do and do not attend for breast cancer screening. Breast Cancer Res. 2002;4(1):R1. doi:10.1186/bcr418.

26. The West of Scotland Coronary Prevention Study Group. Computerised record linkage: compared with traditional patient follow-up methods in clinical trials and illustrated in a prospective epidemiological study. J Clin Epidemiol. 1995;48:1441-52. doi:10.1016/0895-4356(95)00530-7.

27. Kendrick S, Clarke J. The Scottish Record Linkage System. Health Bull (Edinb). 1993;51:72-9.

28. Information and Statistics Division NHS Scotland. NHS Scotland Quality Assurance Report on Acute Inpatient/Day case Data 2001-2002, Vol. 2005. Scotland: ISD; 2004.

29. Liu B, Sweetland S, Beral V, Green J, Balkwill A, Casabonne D. Self-reported information on joint replacement and cholecystectomy agrees well with that in medical records. J Clin Epidemiol. 2007;60:1190-4. doi:10.1016/j.jclinepi.2007.02.007. 